\title{
Predictive value of subclinical autistic traits at age 14-15 months for behavioural and cognitive problems at age 3-5 years
}

\author{
Esmé Möricke $\cdot$ Sophie H. N. Swinkels • \\ Karin T. Beuker $\cdot$ Jan K. Buitelaar
}

Received: 23 June 2009/ Accepted: 3 March 2010/Published online: 27 March 2010

(C) The Author(s) 2010. This article is published with open access at Springerlink.com

\begin{abstract}
It is unclear whether subclinical autistic traits at very young age are transient or stable, and have clinical relevance. This study investigated the relationship between early subclinical autistic traits and the occurrence of later developmental and behavioural problems as well as problems in cognitive and language functioning. Parents of infants aged 14-15 months from the general population completed the Early Screening of Autistic Traits Questionnaire (ESAT). Three groups of children with high, moderate, and low ESAT-scores (total $n=103$ ) were selected. Follow-up assessments included the CBCL $1 \frac{1}{2}-5$ at age 3 years, and the SCQ, the ADI-R, the ADOS-G, a non-verbal intelligence test, and language tests for comprehension and production at age 4-5 years. None of the children met criteria for autism spectrum disorder at follow-up. Children with high ESAT-scores at 14-15 months showed significantly more internalizing and externalizing problems at age 3 years and scored significantly lower on language tests at age $4-5$ years than children with moderate or low ESAT-scores. Further, significantly more children with high ESAT-scores $(14 / 26,53.8 \%)$ than with moderate and low ESAT-scores $(5 / 36,13.9 \%$ and $1 / 41$, $2.4 \%$, respectively) were in the high-risk/clinical range on one or more outcome domains (autistic symptoms,
\end{abstract}

E. Möricke · S. H. N. Swinkels · K. T. Beuker .

J. K. Buitelaar $(\bowtie)$

Department of Psychiatry (966),

Nijmegen Centre for Evidence-Based Practice (NCEBP),

Radboud University Nijmegen Medical Centre,

P.O. Box 9101, 6500 HB Nijmegen, The Netherlands

e-mail: J.Buitelaar@psy.umcn.nl

E. Möricke · S. H. N. Swinkels - K. T. Beuker · J. K. Buitelaar Karakter Child and Adolescent Psychiatry University Centre, Nijmegen, The Netherlands behavioural problems, cognitive and language abilities). Subclinical autistic traits at 14-15 months predict later behavioural problems and delays in cognitive and language functioning rather than later ASD-diagnoses. The theoretical implications of the findings lie in the pivotal role of early social and communication skills for the development of self-regulation of emotions and impulses. The practical implications bear on the early recognition of children at risk for behavioural problems and for language and cognitive problems.

Keywords Autistic traits - Behavioural problems . Cognitive abilities · Young children · General population

\section{Introduction}

Autism spectrum disorders (ASD) are neurodevelopmental disorders characterized by qualitative impairments in reciprocal social interactions and (non-)verbal communication, as well as by restricted, repetitive, and stereotyped patterns of behaviour, interests, and activities [4]. There is consensus about the disorders that comprise this spectrum, with autistic disorder, Asperger's disorder, and pervasive developmental disorder-not otherwise specified (PDD-NOS) as the most typical examples [44]. However, there is also a borderland between ASD and non-ASD in which individuals with subclinical autistic traits can be found. These are defined as traits which are similar to autistic symptoms, but which are milder and/or less in number, and below the diagnostic threshold for ASD. In this paper, we will focus on such subclinical autistic traits at age 14-15 months.

ASD have shown to be very stable over time in follow-up studies in clinical samples of various ages. However, diagnoses are less stable in children who are younger than 
2 years of age, who are functioning on a relatively high level, and/or who show less or milder symptoms of ASD [20,21]. It is also unclear whether subclinical autistic traits at very young age are transient or stable, and have clinical relevance. Given the increasing recognition of the importance of early diagnosis and treatment of ASD, there is a critical need to extend our knowledge about the early manifestations of subclinical autistic traits and use this in guiding our mental health care strategies towards early diagnosis and treatment, so that less severely affected children who are relatively easily trainable can benefit in the long term. Primary caregivers play a key role, because very young children are embedded in and dependent on the relationship with them in a natural environment $[8,21,30,45]$.

Subclinical autistic traits in infants might be confused with problems in achieving milestones for social, communication, emotional, cognitive, and motor skills [46]. Since these developmental problems may resolve over time, similar transience may exist for subclinical autistic traits in infants. However, subclinical autistic traits at a very young age may also prove to be stable, evolving precursors of ASD which will become clinically manifest by 36 months or later. This is called homotypic continuity [17] and might apply particularly to children with Asperger's disorder or PDD-NOS who are relatively able and have fairly normal language skills. These children may go clinically unnoticed initially and will only draw attention of parents, teachers, and professionals later on when higher demands on reciprocal social interactions with peers are made $[10,27,28,43]$.

A second possibility is that subclinical autistic traits at a very young age might be early indicators of non-ASD behavioural problems at a later age, which would be an example of heterotypic continuity [17]. Some children show (subclinical) symptoms of ASD as well as ADHD (attention-deficit/hyperactivity disorder), and therefore both diagnoses have to be considered [32, 35]. In addition, children with ASD are prone to have other co-morbid externalizing and internalizing behavioural problems, deficiencies in social skills, or psychiatric symptoms [18, $34,36]$.

A third possibility is that early subclinical autistic traits are predictors of later problems of cognitive functioning, i.e. intelligence and language. Several studies indicate that individuals with ASD have an unusual degree of unevenness in cognitive abilities, with in general lower verbal than performance IQ [23]. Children with ASD show a wider range of linguistic deficits than their normally developing peers [12, 22]. Cognitive and language abilities seem to be interrelated since non-verbal cognitive ability, joint-attention, imitation, and gestures are found to be concurrent predictors of receptive and expressive language in toddlers with ASD [26].
This study was conducted to examine the relationship between early subclinical autistic traits and the occurrence of later developmental, behavioural, and cognitive problems. With this aim, we measured subclinical autistic traits of 14- to 15-month-old children in the general population using the Early Screening of Autistic Traits Questionnaire (ESAT) $[15,37]$. We tested the hypotheses that children with high levels of autistic traits at age 14-15 months, in comparison with children with moderate and low levels of autistic traits, will (1) express more autistic symptoms and present with more ASD-diagnoses at age 4-5 years; (2) show more externalizing and internalizing behavioural problems at age 3 years; and (3) have more cognitive and language problems at age $4-5$ years.

\section{Methods}

\section{Procedure}

The design and study procedures were approved by the Medical Ethical Committee of University Utrecht Medical Centre. Parents of all children from a total population birth cohort with children born between August 2000 and August 2001 in the province of Utrecht in The Netherlands, were approached through an inoculation organization with the request to complete the ESAT (see further for details) when their child was 14 months old. Children with certain ESAT-scores were selected for the present study. Their parents received written and oral information about the study and signed informed consent. Various instruments were used to assess the development and behaviour of a child over time (Table 1). Parents were asked to fill in behavioural questionnaires at two time points and to participate in a home-visit at age 4-5 years. The visits, which were performed by child psychologists who were blind for the ESAT-score of the child, included an interview and an observation as well as a cognitive assessment focusing on non-verbal intelligence and language development.

\section{Participants}

The distribution of the ESAT-scores of the children in the population $(n=4,107)$ was as follows: $2,840(69.2 \%)$ scored $0,1,048(25.5 \%)$ scored 1, and $219(5.3 \%)$ scored 2 or more. The selection procedure of children from the lowand moderate-scoring groups was straightforward. These groups were relatively large and therefore children were randomly selected. We approached 72 low- and 55 moderate-scoring children. In the high-scoring group the selection procedure was more complicated. First, we excluded two children with severe multiple handicaps 
Table 1 Overview of domains, instruments, and ages at measurement

\begin{tabular}{|c|c|c|c|c|}
\hline \multirow[t]{2}{*}{ Domains } & \multirow[t]{2}{*}{ Instruments } & \multicolumn{3}{|c|}{ Age at measurement } \\
\hline & & $\begin{array}{l}14-15 \text { months } \\
14.5 \pm 1.9^{\mathrm{a}}\end{array}$ & $\begin{array}{l}3 \text { years } \\
37.8 \pm 3.5^{\mathrm{a}}\end{array}$ & $\begin{array}{l}4-5 \text { years } \\
53.0 \pm 5.0^{\mathrm{a}}\end{array}$ \\
\hline \multirow[t]{4}{*}{ Autistic traits } & ESAT & $\times$ & & \\
\hline & SCQ & & & $\times$ \\
\hline & ADI-R & & & $\times$ \\
\hline & ADOS-G & & & $\times$ \\
\hline Behavioural problems & CBCL $1 \frac{1}{2}-5$ & & $x$ & \\
\hline \multirow[t]{3}{*}{ Cognitive functioning } & SON-R $2 \frac{1}{2}-7$ & & & $\times$ \\
\hline & RTB & & & $x$ \\
\hline & STP & & & $x$ \\
\hline
\end{tabular}

ESAT early screening of autistic traits questionnaire, $S C Q$ social communication questionnaire, $A D I-R$ autism diagnostic interview-revised, $A D O S-G$ autism diagnostic observation schedule-generic, $C B C L 1 \frac{1}{2}-5$ child behaviour checklist $1 \frac{1}{2}-5$; SON-R 21/2-7 Snijders-Oomen nonverbal intelligence test $2 \frac{1}{2}-7, R T B$ Reynell test for language comprehension, STP Schlichting test for language production

${ }^{a}$ mean age and standard deviation in months

$(0.9 \%)$, three children with an already known clinical ASD-diagnosis (1.4\%), and 25 children who participated in ADHD- or ODD-research projects performed by other researchers (11.4\%). A total number of 189 high-scoring children remained $(86.3 \%)$. Then, we made a weighted selection, as follows. We started to invite all children with ESAT-scores of 3 or more $(n=30)$ and their parents. Later on, we invited a random selection of children with ESATscores of $2(n=19)$ and their parents. However, not all families could be reached or were willing to participate. Finally, 103 children and their parents participated $(58.5 \%$ of 176 families approached): $39.8 \%$ with low ESAT-scores ( $n=41,26$ boys, 15 girls), $35.0 \%$ with moderate ESATscores ( $n=36,20$ boys, 16 girls), and $25.2 \%$ with high ESAT-scores ( $n=26,15$ boys, 11 girls). The sizes of the scoring groups were determined by constraints in time and money given the investment in the follow-up assessments. The flow chart is represented in Fig. 1.

At the start of the research, the age of the children was 1415 months $(M=14.5$ months, $\mathrm{SD}=1.9$ months $)$. Followup took place around age 3 years $(M=37.8$ months, $\mathrm{SD}=3.5$ months) and between age 4 and 5 years ( $M=53.0$ months, $\mathrm{SD}=5.0$ months). During the first two measurements the groups did not differ in age, but at the time of the home-visit the children in the high-scoring group were significantly older than the other children $(p<0.001)$. There were no significant sex differences between the groups.

\section{Instruments}

\section{Autistic traits}

Autistic traits around age 14 months were measured with the ESAT. The ESAT includes 14 items which are based on early symptoms of autism and which cover the domains of social-communication skills, stereotyped behaviour, reactions to sensory stimuli, and play. Some examples are "Does your child show interest in other children and adults?", "Is the behaviour of your child free from stereotyped repetitive movements?", "Does your child respond normally to sensory stimuli?", "Can your child play with toys or objects in varied ways?" Each item has a dichotomous answer ("yes" or "no") $[15,37]$. Originally, the ESAT was developed as a screening tool for ASD in which a score of 3 or more reflects a positive screen, but in our study we used the ESAT as a measure of subclinical autistic traits.

Autistic traits at age 4-5 years were measured with the Social Communication Questionnaire (SCQ) [6]. It consists of 40 items with "yes" and "no" answers. Typical behaviour is scored as 0 , whereas the absence of normal behaviour or the presence of abnormal behaviour is rated as 1. The official cut-off for ASD is fixed at 15, but for younger children a lower cut-off of 11 seems to be more accurate $[3,13]$. Since we focused on children aged 4-5 years we preferred the latter one, and we considered scores of 11 and above as clinically significant.

The Autism Diagnostic Interview-Revised (ADI-R) [25] and the Autism Diagnostic Observation Schedule-Generic (ADOS-G) [24] were further used to assess symptoms of autism at age 4-5 years. Because of risk estimation and time efficiency, the ADOS-G was only coded for children in the high-scoring group.

\section{Behavioural problems}

Behavioural problems at age 14-15 months were measured by a part of the Utrecht Screening Questionnaire (USQ) 


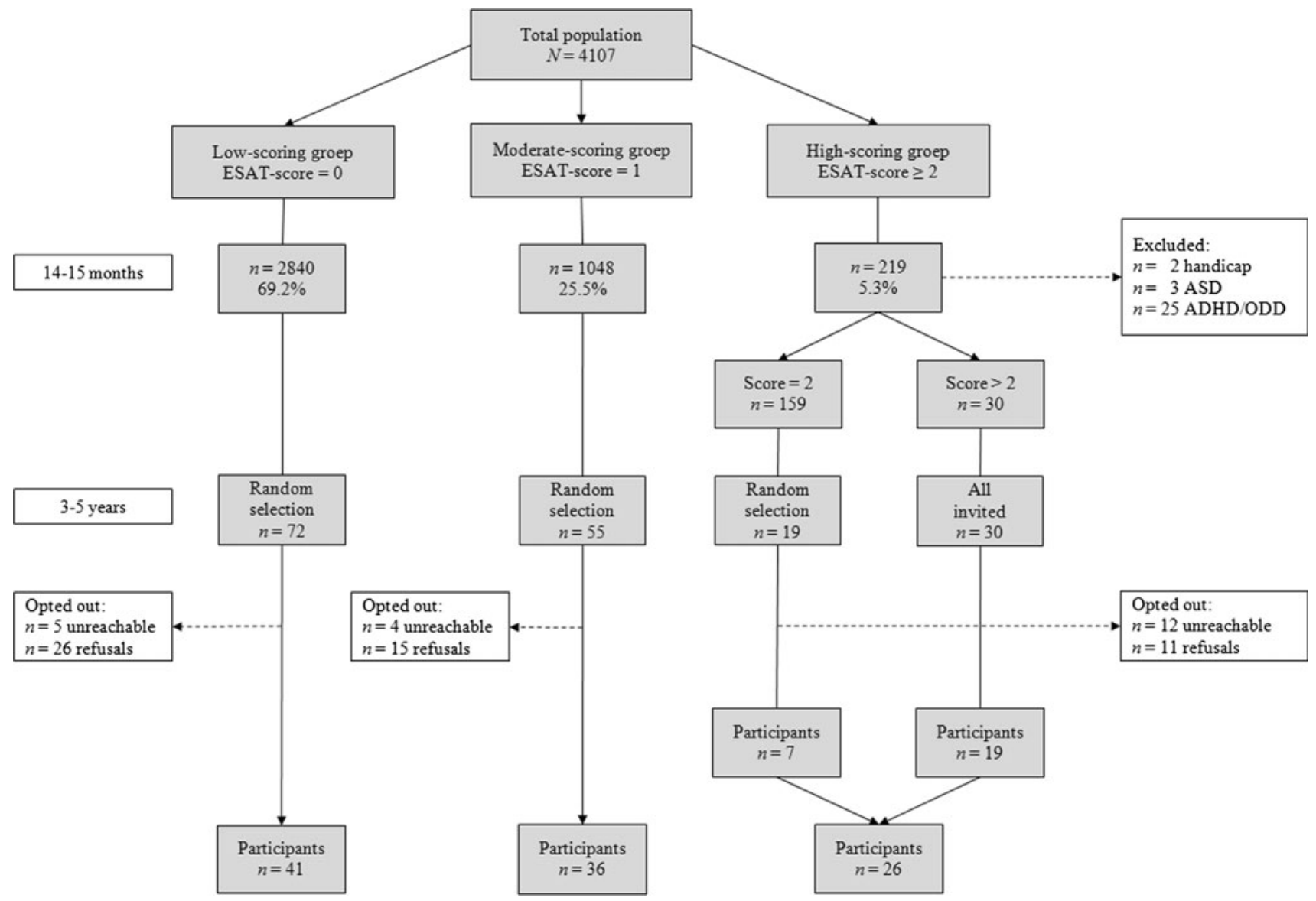

Fig. 1 Flow chart of participants

[5]. We used 60 items regarding externalizing behaviour, internalizing behaviour, and social-communication problems with answers on a three-point Likert-scale (0-1-2) to compute a mean total score. A higher score points at more problematic behaviour.

Behavioural problems at age 3 years were measured with the Dutch version of the Child Behavior CheckList $1 \frac{1}{2}-5$ (CBCL $1 \frac{1}{2}-5$ ) [1, 42]. This is a questionnaire consisting of 100 items with answers on a three-point Likertscale (0-1-2), that reveals information about various externalizing and internalizing problems. Children with scores in the clinical range are at high risk for developing or experiencing serious behavioural problems.

\section{Cognitive abilities}

The child's level of non-verbal intelligence at age 4-5 years was assessed with the Dutch Snijders-Oomen Niet-verbale intelligentietest 2 $1 / 2-7$ (Snijders-Oomen Nonverbal intelligence test $2 \frac{1}{2}-7$; SON-R $2^{1 / 2-7)}$ [38]. This test contains six subtests, which belong either to the performance scale (mosaics, puzzles, patterns) or to the reasoning scale (categories, analogies, situations). For both scales as well as for the total score, IQ-scores with a mean of 100 and a standard deviation of 15 can be computed.

The child's language abilities at age 4-5 years were examined with two Dutch language tests. The Reynell Test voor Taalbegrip (Reynell Test for Language Comprehension; RTB) [41] measures the level of passive language comprehension. It is built up of 12 sections increasing in complexity and difficulty. The Schlichting Test voor Taalproductie (Schlichting Test for Language Production; STP) [33] measures the level of active language production. It consists of three subtests, namely sentence development, word development, and auditory memory. The results are given in standardized IQ-scores.

Statistical analyses

First, we explored the possibilities of generalization of characteristics from high-scoring children included in our sample $(n=26)$. Therefore, we compared the scores of these children with those of high-scoring children not included in our sample $(n=193)$. We used an independent samples t-test to compare the mean total scores of behavioural problems (USQ) at age 14-15 months of both 
groups. Further, we analyzed on which particular ESATitems the high-scoring children failed, and we computed Pearson correlation coefficients between their ESAT-scores and their scores on the five outcome measures. For measures regarding autistic traits (SCQ) and behavioural problems (CBCL 1 1 $1 \frac{2-5}{2}$ ) mean sum scores were calculated on the basis of raw scores. For the measures concerning cognitive abilities (SON-R 2 $1 / 2-7$, RTB, STP) mean standardized IQ-scores were assessed.

Univariate analyses of variance on various levels (total, domain/scale, item) were used to compare the scores on the outcome measures of the three groups with high $(n=26)$, moderate $(n=36)$, and low $(n=41)$ ESAT-scores, followed by Bonferroni post hoc tests to examine which group scores differed significantly. The analyses were performed with and without age as covariate, but the results were comparable, so we only report the latter ones.

To assess the magnitude of the group differences in mean raw and IQ-scores, we established effect sizes (Cohen's $d$ ). Values of $0.20,0.50$, and 0.80 indicate small, moderate, and large effects, respectively [11]. $d_{a}$ refers to effect sizes regarding the high- and moderate-scoring groups, whereas $d_{b}$ refers to effect sizes regarding the highand low-scoring groups. The level of significance was defined as $p \leq 0.05$.

Furthermore, we determined how many children scored in the clinical range on the SCQ, CBCL $1 \frac{1 / 2-5}{2}$, and intelligence and language tests, not only for the whole group but also for each scoring group separately by means of crosstabs. The statistical software package SPSS 14.0 was used for all analyses.

\section{Results}

\section{High-scoring group}

The mean total score of behavioural problems (USQ) of the high-scoring group included $(M=33.42)$ and the highscoring group not included $(M=29.46)$ were compared. The two groups did not differ significantly from each other $(t=-1.639, d f=217, p=0.103)$. This implies that there is no reason to suspect that the results of the relatively small high-scoring group included in our sample cannot be generalized to a larger group of children with high ESATscores.

Children from the high-scoring group had high scores and thus failed on various ESAT-items. Two items were most striking, because more than $50 \%$ of the children had a deviating score. Many children do not always ask for attention when being alone or make stereotypic movements regularly. In this group, some deficits in early skills seem to be related to later problems. Two significant correlations between ESAT-scores and mean total scores on outcome measures were found. Children who have difficulties in expressing their emotions properly at age 14-15 months have a higher risk of experiencing behavioural problems (CBCL 1 1 $1 \frac{2}{2}-5, r=0.505, p=0.008$ ) at age 3 years. Children who cannot make eye-contact easily at age 14-15 months obtain lower scores on measures of language comprehension (RTB, $r=-0.557, p=0.004$ ) and production (STP, $r=-0.589, p=0.002$ ) at age $4-5$ years.

Autistic traits and symptoms

The SCQ was rated separately by both parents of each child. Later on, the father $(97 / 103,94.2 \%)$ and mother (99/103, 96.1\%) ratings of the SCQ were averaged per child $(n=97)$. These mean scores were used in further analyses. At the group level, a small Pearson correlation coefficient $(r=0.21)$ was found between the total ESATscore at age 14-15 months and the total SCQ-score at age 4-5 years. Comparisons of the SCQ mean total, domain, and factor scores of the three groups did not reveal significant differences. However, the total SCQ-score $[F(2,94)=2.41, p=0.095]$ and the domain score "social interaction" $[F(2,94)=2.72, p=0.071]$ showed a trend. Therefore, we also examined scores on the item level. The results for the items "abnormal eye contact" $[F(2,94)=9.31, p<0.001]$ and "unusual sensory interests" $[F(2,94)=4.55, p=0.013]$ were most prominent. Post hoc tests revealed that the high-scoring children had significantly more problems in making eye contact than the other children $\left(d_{a}=0.78 ; d_{b}=0.78\right)$ and that they showed unusual sensory interests considerably more often than the low-scoring children $\left(d_{b}=0.78\right)$.

Behavioural problems

With respect to the CBCL $1 \frac{1}{2}-5$, the univariate analyses showed significant differences between groups on the total score $\left(d_{a}=0.79 ; d_{b}=0.69\right)$, internalizing score $\left(d_{a}=0.63 ; d_{b}=0.60\right)$, externalizing score $\left(d_{a}=0.79\right.$; $\left.d_{b}=0.62\right)$, and the empirical scales "emotionally reactive" $\left(d_{a}=0.71 ; d_{b}=0.55\right)$, "anxious/depressed" $\left(d_{a}=\right.$ $\left.0.61 ; d_{b}=0.56\right)$, "withdrawn" $\left(d_{b}=0.69\right)$, "attention problems" $\left(d_{a}=0.50\right)$, "aggressive behaviour" $\left(d_{a}=\right.$ $\left.0.72 ; \quad d_{b}=0.60\right)$, and "other problems" $\left(d_{a}=0.86\right.$; $d_{b}=0.72$ ). Table 2 gives an overview of the main results. Moreover, significant differences and moderate to large effect sizes were found on 26 items (results available upon request). Bonferroni post hoc tests made clear that children from the high-scoring group experienced more behavioural problems than children from the other groups. 
Table 2 Means, standard deviations, and group differences in behavioural functioning (CBCL 11/2-5) as measured at age 3 years by scoring group $(n=103)$

\begin{tabular}{|c|c|c|c|c|}
\hline \multirow[t]{2}{*}{ CBCL $1 \frac{1}{2}-5$} & \multicolumn{3}{|c|}{ ESAT-score (group) } & \multirow[t]{2}{*}{$F(2,100) ; p$} \\
\hline & $\begin{array}{l}\text { High }(\mathrm{H}) \\
n=26\end{array}$ & $\begin{array}{l}\operatorname{Mod}(\mathrm{M}) \\
n=36\end{array}$ & $\begin{array}{l}\text { Low (L) } \\
n=41\end{array}$ & \\
\hline \multicolumn{5}{|l|}{ Total } \\
\hline Total score & $42.23(25.85)$ & $25.64(14.40)$ & $28.34(11.86)$ & $7.78 ; 0.001^{\mathrm{a}, \mathrm{b}}$ \\
\hline \multicolumn{5}{|l|}{ Main scales } \\
\hline (I) Internalizing & $11.19(9.28)$ & $6.19(6.17)$ & $6.68(5.03)$ & $4.90 ; 0.009^{\mathrm{a}, \mathrm{b}}$ \\
\hline (E) Externalizing & $16.04(8.17)$ & $10.67(4.97)$ & $11.68(5.53)$ & $6.31 ; 0.003^{\mathrm{a}, \mathrm{b}}$ \\
\hline \multicolumn{5}{|l|}{ Empirical scales } \\
\hline (I) Emotionally reactive & $3.42(3.19)$ & $1.67(1.41)$ & $1.98(1.94)$ & $5.37 ; 0.006^{\mathrm{a}, \mathrm{b}}$ \\
\hline (I) Anxious/depressed & $2.77(3.30)$ & $1.19(1.65)$ & $1.37(1.34)$ & $4.93 ; 0.009^{\mathrm{a}, \mathrm{b}}$ \\
\hline (I) Somatic complaints & $2.77(3.02)$ & $2.00(2.98)$ & $2.27(2.41)$ & $0.58 ; 0.559$ \\
\hline (I) Withdrawn & $2.23(1.86)$ & $1.33(1.39)$ & $1.07(1.47)$ & $4.59 ; 0.012^{\mathrm{b}}$ \\
\hline Sleep problems & $2.50(3.43)$ & $2.19(2.53)$ & $2.29(2.26)$ & $0.10 ; 0.906$ \\
\hline (E) Attention problems & $3.08(2.13)$ & $1.72(1.49)$ & $2.12(1.68)$ & $4.68 ; 0.011^{\mathrm{a}}$ \\
\hline (E) Aggressive behaviour & $12.96(6.64)$ & $8.94(4.34)$ & $9.46(4.86)$ & $5.12 ; 0.008^{\mathrm{a}, \mathrm{b}}$ \\
\hline Other problems & $12.50(7.85)$ & $6.92(4.81)$ & $8.05(3.76)$ & $8.69 ;<0.001^{\mathrm{a}, \mathrm{b}}$ \\
\hline
\end{tabular}

Note: Low mean scores close to zero indicate normal behaviour. Higher mean scores refer to more problematic behaviour

${ }^{a}$ Significant difference between group $\mathrm{H}$ and $\mathrm{M}(p \leq 0.05)$

${ }^{\mathrm{b}}$ Significant difference between group $\mathrm{H}$ and $\mathrm{L}(p \leq 0.05)$

\section{Cognitive abilities}

Regarding intelligence, the mean scores, standard deviations, and group differences of the non-verbal intelligence test are given in Table 3. The univariate analyses of the SON-R 21/2-7 did not reveal significant group differences at the level of the total score and the performance and reasoning scales. A significant difference $[F(2,100)=$ 3.48, $p=0.034, d_{a}=-0.58$ ] was only found on the subtest "situations", which measures insight in mutual and meaningful relations between persons, objects, space and time in concrete situations. Children from the high-scoring group had lower mean scores and experienced more difficulties in interpreting situations than children from the moderate-scoring group.

Regarding language, the univariate analysis of the RTB total score, the STP total score, and the subtests "sentence development" and "word development" showed significant differences between groups (Table 3). The Bonferroni post hoc tests demonstrated that children from the highscoring group had significantly lower mean scores on the RTB than children from the moderate- and low-scoring groups $\left(d_{a}=-0.59 ; d_{b}=-0.78\right)$. With respect to the STP, we noticed that the high-scoring group had the worst scores and that the low-scoring group had the best scores for the total test $\left(d_{b}=-0.87\right)$ as well as for the subtests "sentence development" $\left(d_{b}=-0.76\right)$ and "word development" $\left(d_{b}=-0.86\right)$. The moderate-scoring group performed in between. This implies that children from the high-scoring group had relatively more problems in language comprehension and production (sentence and word development) than children from the other groups.

\section{Clinical range}

None of the children reached the cut-off for ASD on the ADI-R or ADOS-G. On the SCQ, none of the children scored above the general cut-off of 15 . However, there were eight children who reached the cut-off of 11, and who thus scored in the clinical range for young children: one in the low-scoring group, three in the moderate-scoring group, and four in the high-scoring group. On the CBCL $1 \frac{1}{2}-5$ at age 3 years, seven children (one from the moderate-scoring group and six from the high-scoring group) had a total score in the clinical range. On the SON-R $2 \frac{1}{2}-7$, five children, two of whom belonged to the moderate-scoring group and three to the high-scoring group, had a total IQ-score below 85. On the RTB, eight children (one in the moderate-scoring group and seven in the high-scoring group) had an IQ-score below 85, and on the STP, seven children (one in the moderate-scoring group and six in the high-scoring group) had an IQ-score below 85 . 
Table 3 Means, standard deviations, and group differences of non-verbal intelligence (SON-R 21/2-7), language comprehension (RTB), and language production (STP) as measured at age $4-5$ years by scoring group $(n=103)$

\begin{tabular}{|c|c|c|c|c|}
\hline & \multicolumn{4}{|c|}{ ESAT-score (group) } \\
\hline & High $(\mathrm{H})$ & $\operatorname{Mod}(\mathrm{M})$ & Low (L) & $F ; p$ \\
\hline & $n=26$ & $n=36$ & $n=41$ & \\
\hline \multicolumn{5}{|l|}{ SON-R 21/2-7 } \\
\hline Total score & $108.7(19.2)$ & $116.7(20.1)$ & $115.7(14.4)$ & $(2,100)=1.72 ; 0.184$ \\
\hline \multicolumn{5}{|l|}{ RTB } \\
\hline Total score & $100.3(16.3)$ & $109.3(14.5)$ & $111.5(11.8)$ & $(2,99)=5.23 ; 0.007^{\mathrm{a}, \mathrm{b}}$ \\
\hline \multicolumn{5}{|l|}{ STP } \\
\hline Total score & $98.2(14.6)$ & $104.8(13.8)$ & $109.6(11.1)$ & $(2,99)=6.02 ; 0.003^{\mathrm{b}}$ \\
\hline Sentence development & $98.8(15.3)$ & $107.3(15.5)$ & $109.6(13.0)$ & $(2,99)=4.44 ; 0.014^{\mathrm{b}}$ \\
\hline Word development & $97.5(16.6)$ & $103.3(12.8)$ & $109.7(11.0)$ & $(2,98)=6.81 ; 0.002^{\mathrm{b}}$ \\
\hline Auditory memory ${ }^{\mathrm{c}}$ & $103.9(15.1)$ & $108.8(11.1)$ & $108.4(10.2)$ & $(2,83)=0.88 ; 0.418$ \\
\hline
\end{tabular}

Note: The general mean and standard deviation are 100 and 15 IQ-points respectively. Lower scores point at worse performance. Higher scores refer to better achievements

Data of RTB/STP of one child from the high-scoring group are missing; for another child, data on subtest word development (STP) are missing

a Significant difference between group $\mathrm{H}$ and $\mathrm{M}(p \leq 0.05)$

${ }^{\mathrm{b}}$ Significant difference between group $\mathrm{H}$ and $\mathrm{L}(p \leq 0.05)$

${ }^{\mathrm{c}}$ Due to a restricted age range this subtest could not be assessed in all children: group $\mathrm{H} n=12$; group $\mathrm{M} n=35$; group L $n=39$

In total, 20 children (19.4\% of 103) had scores in the clinical range on one or more outcome domains. Most of them $(n=15)$ scored in the clinical range on only one domain, but some $(n=5)$ were in the clinical range on two domains. No child scored on all three domains. Proportionally, a significantly higher number of children from the high-scoring group $(14 / 26,53.8 \%)$ showed scores in the clinical range in comparison with children from the moderate- and low-scoring groups $(5 / 36,13.9 \%$ and $1 / 41,2.4 \%$, respectively; Chi-Square test $\chi^{2}=27.953, d f=2, p<0.001$ ). Additional results are represented visually in a bar chart (Fig. 2).

\section{Discussion}

This study was developed to examine the predictive value of subclinical autistic traits at age 14-15 months for (1) ASD-symptoms, (2) non-ASD behavioural problems, and (3) cognitive functioning 2-4 years later. We sampled children with high, moderate, and low scores on autistic traits from the general population and excluded children who already had been diagnosed with ASD at an early age because our study focused on children with subclinical autistic traits only.

The children with abnormal scores who are included in the high-scoring group seem to be representative of all children with high ESAT-scores. Therefore, there is no reason to suspect that the results of our high-scoring group cannot be generalized. The children failed on various

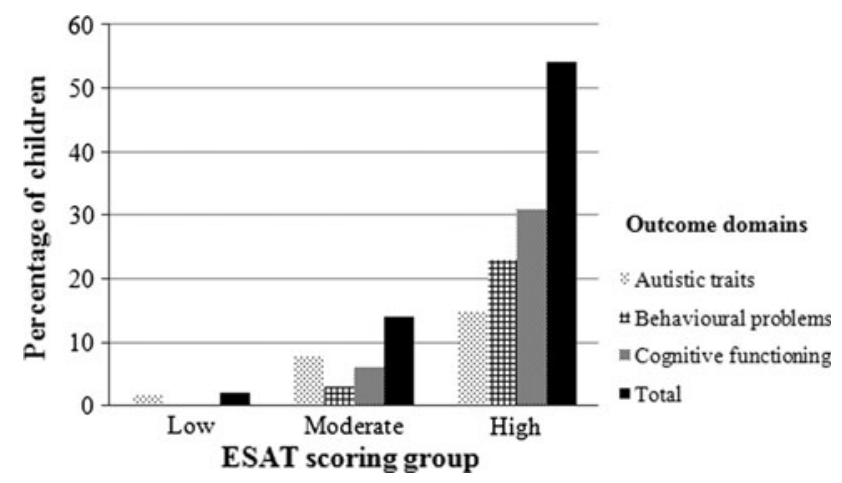

Fig. 2 Bar chart showing percentages of children with scores in the clinical range. Note: A considerable percentage of children with a high ESAT-score at age 14-15 months scored in the clinical range on one or more outcome domains at age 3 or 4-5 years. In contrast, only a small percentage of children with a low ESAT-score scored in the clinical range

ESAT-items. More than $50 \%$ of the children had a deviating score on the items "asking attention" and "stereotypic movements". Some deficits in early skills seem to be related to later problems. Difficulties in expressing emotions at age 14-15 months may be predictive of behavioural problems (CBCL $1 \frac{1}{2}-5$ ) at age 3 years. Inadequate eye-contact at age 14-15 months may be a precursor of delays in language comprehension (RTB) and production (STP) at age 4-5 years.

We were unable to find support for our first hypothesis that predicted subclinical autistic traits at age 14-15 months to be homotypic precursors for ASD at age 4-5 years. None 
of the children satisfied the criteria for a clinical ASDdiagnosis based on the ADI-R or ADOS-G. However, children from the high-scoring ESAT-group scored somewhat higher on the SCQ as a whole and on the domain "social interaction", and scored significantly higher on the items "abnormal eye contact" and "unusual sensory interests" than children from the moderate- and low-scoring ESAT-groups. Nevertheless, our results indicate that there is hardly any continuity of parent-reported early subclinical autistic traits measured with the ESAT at age 14-15 months and similar autistic traits measured with the SCQ at age 45 years. Whereas few children from the high-scoring ESAT-group did present with clinical scores (SCQ 11 and above) at age 4-5 years, the majority had SCQ-scores below the cut-off of 11 . Further, some children from the moderate- and low-scoring ESAT-groups reached SCQscores equal to or higher than 11. These findings are in contrast with the numerous data pointing to rather strong continuity over time of ASD-conditions reaching the level of clinical severity [20,21]. Obviously, clinical severity is closely linked with persistence over time. This may be explained by the fact that greater clinical severity of ASD has been found to be related to a more abnormal early development and functioning of the brain, which in turn may be the driving force affecting the further development of cognitive, language, communicative, social, and emotional functions [2, 14].

We found more support for our second hypothesis that predicted subclinical autistic traits to show heterotypic continuity with later externalizing and internalizing behavioural problems. Our results showed that children from the high-scoring ESAT-group had significantly more externalizing and internalizing behavioural problems than children from the other groups at age 3 years. On the individual level, seven children, of whom six belonged to the high-scoring group, had a total-CBCL-score in the clinical range. Early subclinical autistic traits thus seem to be precursors of serious behavioural problems 2 years later. They seem to reflect a more global risk that does not differentiate between externalizing and internalizing types of problems. Mastery of early social and communicative skills may be closely linked with the development of selfregulation and be pivotal for the proper development of other functions. Contrariwise, poor ability to control and regulate activity, impulses, and emotions may pave the way to later externalizing and internalizing behavioural problems [17, 19, 29, 31].

With the third hypothesis we investigated the relation between subclinical autistic traits at age 14-15 months and cognitive and language abilities at age $4-5$ years. In contrast to our expectations, we did not find differences between the ESAT-groups in levels of non-verbal intelligence (SON-R $2 \frac{1}{2}-7$ ), except for the subtest "situations".
This means that children from the high-scoring ESATgroup, who have an average total IQ-score, perform well overall, but that they are less able to interpret the logical coherence of (social) situations than children from the moderate-scoring ESAT-group. We were also unable to find an unusual degree of unevenness in cognitive abilities often seen in children with ASD [23], although early subclinical autistic traits were associated with significantly lower levels of language comprehension (RTB) and production (STP) at age 4-5 years. However, significantly more children from the high-scoring ESAT-group than from the other groups had a non-verbal IQ and/or language comprehension and production scores below 85. Our results thus indicate that early subclinical autistic traits are precursors or early manifestations of later cognitive and language problems. This fits with recent findings in a general population sample study in Norway in which parents of infants with high ESAT-scores also report more communication and language problems at the age of 18 months [7]. Since the ESAT does not comprise items regarding language, this reflects the close link between early social and communication skills measured with the ESAT and the development of language and cognition. Similar results were found in two other longitudinal studies focusing on predictors of language acquisition and communication development in young children with ASD $[39,40]$.

Together, these findings demonstrate that early autistic traits are precursors of or risk factors for especially externalizing and internalizing behavioural problems and/or cognitive and language problems at age 3-5 years. More than $50 \%$ of the children in the high-scoring ESAT-group suffer from problems in one or two outcome domains. Though these problems are not well marked clinically, these children can be considered to be at high risk for failing to establish adequate levels of psychosocial functioning and for developing psychiatric disorders. Children with Asperger's disorder or PDD-NOS are unlikely to show enough symptoms early on to be picked up. A followup of this sample may reveal valuable information about the course of development and behaviour in middle childhood. Therefore, we intend to contact the parents in the near future, and to inquire about the child's present level of functioning in various domains, as well as possible current problems, diagnosis, and treatment.

Our study has some limitations, such as the modest sample size, as well as the use of various measures of autistic symptoms, behavioural problems, cognition, and language at different ages. However, it is not feasible to use exactly the same measures in children as young as 1415 months to relatively 'old' 4- to 5-year-olds. Therefore, we chose to use measures which were most suitable for these domains at a particular age. Another limitation is the 
shortage of validated parental questionnaires for assessing autistic traits around age 4-5 years. The SCQ might be less suitable for detecting subtle problems in higher functioning and/or younger children in general populations than for determining severe problems in lower functioning and/or older children in high-risk populations $[3,9,13,16]$. The strength of this project is the use of a longitudinal design in a sample drawn from the general population.

\section{Conclusion}

The implications of our findings lie in the early recognition of cognitive and language problems and/or behavioural problems rather than in the early detection of ASD. Further research is needed to study young children with subclinical autistic traits and to learn more about the neurobiological, cognitive, and behavioural mechanisms that determine their development. Clinicians working with young children who show developmental and/or behavioural problems should be cautious in diagnosing ASD, because (subclinical) autistic traits and related diagnostic labels of ASD are not reliably predictive at that age. The long-term stability of these traits is questionable, unless symptoms are convincing. However, it is important to recognize the presence of subclinical autistic traits and to consider them as red flags which require referral to a specialist for early diagnosis and treatment, because these traits might point at other behavioural and/or cognitive and language problems. This is especially true when parents have clinical concerns or worries. Early intervention offers opportunities to improve behaviour and development, and to prevent the appearance and escalation of problems at a later age. Clinicians should communicate this clearly to parents and should emphasize the importance of follow-up evaluation because diagnosis (if any) will become clearer as their child grows older $[8,21,30,45]$.

\begin{abstract}
Acknowledgments This research is part of the SOSO-project which is financially supported by a grant from the Dutch Organization for Scientific Research (ZonMw CZ-TT 940-38-045 Research Program Chronic Diseases) and by grants from the participating centres, namely University Utrecht Medical Centre, Radboud University Nijmegen Medical Centre, and Karakter Child and Adolescent Psychiatry University Centre Nijmegen, The Netherlands. We are very grateful to the parents who were willing to participate in the research by filling in questionnaires and by taking part in an interview, and also to those children who were subjected to many tests during the home visits.
\end{abstract}

Open Access This article is distributed under the terms of the Creative Commons Attribution Noncommercial License which permits any noncommercial use, distribution, and reproduction in any medium, provided the original author(s) and source are credited.

\section{References}

1. Achenbach TM, Rescorla LA (2000) Manual for the ASEBA preschool forms \& profiles. Research Center for Children, Youth, \& Families, University of Vermont, Burlington, VT

2. Acosta MT, Pearl PL (2004) Imaging data in autism: from structure to malfunction. Semin Pediatr Neurol 11:205-213

3. Allen CW, Silove N, Williams K, Hutchins P (2007) Validity of the Social Communication Questionnaire in assessing risk of autism in preschool children with developmental problems. J Autism Dev Disord 37:1272-1278

4. American Psychiatric Association (2000) Diagnostic and statistical manual of mental disorders, 4 th rev edn. Washington, DC

5. Beernink AC, Swinkels SHN, Buitelaar JK (2007) Problem behavior in a community sample of 14- and 19-month-old children: common versus uncommon behaviors, structure, and stability. Eur Child Adolesc Psychiatry 16:271-280

6. Berument SK, Rutter M, Lord C, Pickles A, Bailey A (1999) Autism Screening Questionnaire: diagnostic validity. Br J Psychiatry 175:444-451

7. Beuker KT, Schjolberg S, Kveim Lie K, Stoltenberg C, Swinkels SHN, Buitelaar JK (2009) M-CHAT and ESAT as screening questionnaires for autism spectrum disorders at 18 months in the general population: issues of overlap and associations with clinical referrals. Manuscript submitted for publication

8. Bryson SE, Rogers SJ, Fombonne E (2003) Autism spectrum disorders: early detection, intervention, education, and psychopharmacological management. Can J Psychiatry 48:506-516

9. Chandler S, Charman T, Baird G, Simonoff E, Loucas T, Meldrum D, Scott M, Pickles A (2007) Validation of the Social Communication Questionnaire in a population cohort of children with autism spectrum disorders. J Am Acad Child Adolesc Psychiatry 46:1324-1332

10. Church C, Alisanski S, Amanullah S (2000) The social, behavioural, and academic experiences of children with Asperger syndrome. Focus Autism and Other Dev Disabl 15:12-20

11. Cohen J (1988) Statistical power analysis for the behavioural sciences, 2nd edn. Lawrence Erlbaum Associates, Hillsdale

12. Condouris K, Meyer E, Tager-Flusberg H (2003) The relationship between standardized measures of language and measures of spontaneous speech in children with autism. Am J Speech Lang Pathol 12:349-358

13. Corsello C, Hus V, Pickles A, Risi S, Cook EH Jr, Leventhal BL, Lord C (2007) Between a ROC and a hard place: decision making and making decisions about using the SCQ. J Child Psychol Psychiatry 48:932-940

14. Courchesne E (2002) Brain development in autism: early overgrowth followed by premature arrest of growth. Ment Retard Dev Disabil Res Rev 10:106-111

15. Dietz C, Swinkels SHN, Van Daalen E, Van Engeland H, Buitelaar JK (2006) Screening for autistic spectrum disorder in children aged 14-15 months. II: population screening with the Early Screening of Autistic Traits Questionnaire (ESAT). Design and general findings. J Autism Dev Disord 36:713-722

16. Eaves LC, Wingert HD, Ho HH, Mickelson ECR (2006) Screening for autism spectrum disorders with the Social Communication Questionnaire. J Dev Behav Pediatr 27:S95-S103

17. Fox NA, Henderson HA (1999) Does infancy matter? Predicting social behaviour from infant temperament. Infant Behav Dev 22:445-455

18. Gadow KD, DeVincent CJ, Pomeroy J, Azizian A (2004) Psychiatric symptoms in preschool children with PDD and clinic and comparison samples. J Autism Dev Disord 34:379-393

19. Keenan K, Shaw D, Delliquadri E, Giovannelli J, Walsh B (1998) Evidence for the continuity of early problem behaviours: 
application of a developmental model. J Abnorm Child Psychol 26:441-454

20. Kleinman JM, Ventola PE, Pandey J, Verbalis AD, Barton M, Hodgson S, Green J, Dumont-Mathieu T, Robins DL, Fein D (2008) Diagnostic stability in very young children with autism spectrum disorders. J Autism Dev Disord 38:606-615

21. Landa RJ (2008) Diagnosis of autism spectrum disorders in the first 3 years of life. Nat Clin Pract Neurol 4:138-147

22. Lewis FM, Murdoch BE, Woodyatt GC (2007) Linguistic abilities in children with autism spectrum disorder. Res Autism Spectr Disord 1:85-100

23. Lincoln AJ, Allen MH, Kilman A (1995) The assessment and interpretation of intellectual abilities in people with autism. In: Schopler E, Mesibov GB (eds) Learning and cognition in autism. Plenum Press, New York, pp 89-117

24. Lord C, Risi S, Lambrecht L, Cook EH Jr, Leventhal BL, DiLavore PC, Pickles A, Rutter M (2000) The Autism Diagnostic Observation Schedule-Generic: a standard measure of social and communication deficits associated with the spectrum of autism. $\mathbf{J}$ Autism Dev Disord 30:205-223

25. Lord C, Rutter M, Le Couteur A (1994) Autism Diagnostic Interview-Revised: a revised version of a diagnostic interview for caregivers of individuals with possible pervasive developmental disorders. J Autism Dev Disord 24:659-685

26. Luyster RJ, Kadlec MB, Carter A, Tager-Flusberg H (2008) Language assessment and development in toddlers with autism spectrum disorders. J Autism Dev Disord 38:1426-1438

27. Macintosh K, Dissanayake C (2006) A comparative study of the spontaneous social interactions of children with high-functioning autism and children with Asperger's disorder. Autism 10:199220

28. Macintosh K, Dissanayake C (2006) Social skills and problem behaviours in school aged children with high-functioning autism and Asperger's disorder. J Autism Dev Disord 36:1065-1076

29. Muris P, Ollendick TH (2005) The role of temperament in the etiology of child psychopathology. Clin Child Fam Psychol Rev 8:271-289

30. Nadel S, Poss JE (2007) Early detection of autism spectrum disorders: screening between 12 and 24 months of age. J Am Acad Nurse Pract 19:408-417

31. Nigg JT (2006) Temperament and developmental psychopathology. J Child Psychol Psychiatry 47:395-422

32. Nijmeijer JS, Minderaa RB, Buitelaar JK, Mulligan A, Hartman CA, Hoekstra PJ (2008) Attention-deficit/hyperactivity disorder and social dysfunctioning. Clin Psychol Rev 28:692-708

33. Schlichting JEPT, Van Eldik MCM, Lutje Spelberg HC, Van der Meulen SJ, Van der Meulen BF (1998) Schlichting Test voor Taalproductie. Handleiding [Schlichting Test for Language Production. Manual]. Swets \& Zeitlinger, Lisse
34. Simonoff E, Pickles A, Charman T, Chandler S, Loucas T, Baird G (2008) Psychiatric disorders in children with autism spectrum disorders: prevalence, comorbidity, and associated factors in a population-derived sample. J Am Acad Child Adolesc Psychiatry 47:921-929

35. Sinzig J, Walter D, Doepfner M (2009) Attention deficit/hyperactivity disorder in children and adolescents with autism spectrum disorder: symptom or syndrome? J Atten Disord online

36. Sverd J (2003) Psychiatric disorders in individuals with pervasive developmental disorder. J Psychiatr Pract 9:111-127

37. Swinkels SHN, Dietz C, Van Daalen E, Kerkhof IHGM, Van Engeland H, Buitelaar JK (2006) Screening for autistic spectrum in children aged 14 to 15 months. I: the development of the Early Screening of Autistic Traits Questionnaire (ESAT). J Autism Dev Disord 36:723-732

38. Tellegen PJ, Winkel M, Wijnberg-Williams BJ, Laros JA (2003) Snijders-Oomen Niet-verbale intelligentietest SON-R 2⿺辶2-7. Handleiding en verantwoording [Snijders-Oomen Non-verbal intelligence test SON-R 21/2-7. Manual and justification]. Hogrefe Verlag, Göttingen

39. Thurm A, Lord C, Lee LC, Newschaffer C (2007) Predictors of language acquisition in preschool children with autism spectrum disorders. J Autism Dev Disord 37:1721-1734

40. Toth K, Munson J, Meltzoff AN, Dawson G (2006) Early predictors of communication development in young children with autism spectrum disorder: joint attention, imitation, and toy play. J Autism Dev Disord 36:993-1005

41. Van Eldik MCM, Schlichting JEPT, Lutje Spelberg HC, Van der Meulen BF, Van der Meulen SJ (2001) Reynell Test voor Taalbegrip. Handleiding [Reynell Test for Language Comprehension. Manual]. Swets \& Zeitlinger, Lisse

42. Verhulst FC, Van der Ende J, Koot HM (1996) Handleiding voor de CBCL/4-18 [Manual for the CBCL/4-18]. Department of Child and Adolescent Psychiatry, Sophia Children's Hospital, Erasmus Medical Centre, Rotterdam

43. Walker DR, Thompson A, Zwaigenbaum L, Goldberg J, Bryson SE, Mahoney WJ, Strawbridge CP, Szatmari P (2004) Specifying PDD-NOS: a comparison of PDD-NOS, Asperger syndrome, and autism. J Am Acad Child Adolesc Psychiatry 43:172-180

44. Willemsen-Swinkels SHN, Buitelaar JK (2002) The autistic spectrum: subgroups, boundaries, and treatment. Review. Psychiatr Clin North Am 25:811-836

45. Woods JJ, Wetherby AM (2003) Early identification of and intervention for infants and toddlers who are at risk for autism spectrum disorder. Lang Speech Hear Serv Sch 34:180-193

46. Zeanah CH, Boris NW, Larrieu JA (1997) Infant development and developmental risk: a review of the past 10 years. J Am Acad Child Adolesc Psychiatry 36:165-178 